\title{
Monitoramento pós-mercado dos testes rápidos para COVID-19: enfrentamento da pandemia
}

\author{
Post-market monitoring of rapid diagnostic tests for COVID-19: \\ confronting the pandemic
}

\begin{abstract}
Marisa Coelho Adatil,* iD Álvaro da Silva Ribeiro' (iD Caique de Assis Cirilo' iD Danielle Copello Vigo' Danielle Custódio Deslandes do Passo' (iD)

Gabriella Pires da Silva Macedo' iD Helena Cristina Balthazar Guedes Borges' iD
\end{abstract}

José Roberto Niemeyer de Castro' Lívia Vieira Teixeira' iD

Marli Melo da Silva' iD

Paulo Cesar Moreno Guimarães' (iD)

Raimundo Ismael Freitas de Maria' iD

Renata Malachini Maia' (iD

Roberto Machado do Passo' (iD

Rogério Soares da Cunha'

Valeria Furtado de Mendonça' iD

Yasmin Rosa Ribeiro' ID

Ana Carolina Moreira Marino Araújo" iD

Julierme Gonçalves da Silva"II iD Nélio Cézar de Aquino"II (ID)

1 Laboratório de Sangue e Hemoderivados, Departamento de Imunologia, Instituto Nacional de Controle de Qualidade em Saúde, Fundação Oswaldo Cruz (INCQS/ Fiocruz), Rio de Janeiro, RJ, Brasil

" Gerência de Inspeção e Fiscalização de Produtos para Saúde (GIPRO), Gerência-Geral de Inspeção e Fiscalização Sanitária (GGFIS), Agência Nacional de Vigilância Sanitária (Anvisa), Brasília, DF, Brasil

III Gerência de Laboratórios de Saúde Pública (GELAS), Agência Nacional de Vigilância Sanitária (Anvisa), Brasília, DF, Brasil

\section{* E-mail: marisa.adati@incqs.fiocruz.br}

\section{RESUMO}

Introdução: Em dezembro de 2019, foi descoberto na cidade de Wuhan, China, um primeiro grupo de pacientes com sintomas de uma pneumonia atípica. Em 7 de janeiro de 2020, o seu agente etiológico foi identificado: tratava-se de um novo betacoronavírus, geneticamente similar ao SARS-CoV-1, constituído de fita simples de RNA, vírus envelopado de 50-200 nm de diâmetro designado como SARS-CoV-2, e a doença foi denominada COVID-19. Em 30 de janeiro, a Organização Mundial da Saúde declarou Emergência de Saúde Pública de Importância Internacional em razão da disseminação desse novo vírus. Os testes para detecção sorológica de anticorpos IgM e IgG fornecem uma estimativa da resposta imune ao SARS-CoV-2, com destaque para os Testes Rápidos (TR) que são simples e acessíveis fornecendo resultados em 5-30 min. Esses testes são sensibilizados com antígenos/anticorpos conjugados ao ouro coloidal, capturando proteínas específicas presentes no soro, plasma ou sangue de pacientes infectados. Objetivo: Demonstrar a análise efetuada nos TR para diagnóstico da COVID-19, em atendimento a legislação vigente, no período de 2 de abril a 18 de agosto de 2020. Método: Durante o mês de março de 2020, foram cedidas 25 amostras de soro/plasma, sem qualquer identificação, excedentes dos testes efetuados em indivíduos com diagnóstico confirmado de infecção pelo SARS-CoV-2 pela técnica de RT-PCR provenientes de serviços de saúde (Instituto Nacional de Infectologia Evandro Chagas - INI e Instituto Estadual do Cérebro Paulo Niemeyer - IEC) localizados na região metropolitana do estado do Rio de Janeiro. As amostras obtidas para a confecção de painel sorológico foram armazenadas a $-20^{\circ} \mathrm{C}$ até o momento do uso. Concomitantemente, um painel de amostras com reatividade confirmada para anticorpos IgM e IgG da COVID-19 foi sendo confeccionado ao longo da pandemia e as amostras utilizadas foram avaliadas frente a três TR, de diferentes composições antigênicas ou diferentes marcas; dois testes ELISA para IgM e IgG; dois testes de quimioluminescência e quando aplicável, um teste molecular. Para avaliação da especificidade dos produtos encaminhados, foram selecionadas amostras de plasma excedentes de doação, sabidamente negativas para HIV, HTLV, hepatite B e C, doença de chagas e sífilis coletadas nos anos de 2013 e 2014, na Região Sul do país, período no qual o SARS-CoV-2 era inexistente. Além de amostras Verdadeiro Positivas (VP) e Verdadeiro Negativas (VN), ainda foram incluídas na avaliação amostras de soro ou plasma interferentes com reatividade para HIV, HCV, HTLV, HBsAg, doença de chagas, sífilis e dengue. Resultados: Dos 178 lotes de TR, 74,1\% foram provenientes da China e 25,9\%, do Brasil, da Alemanha, da Coreia do Sul, do Canadá, dos EUA, da Cingapura, da Irlanda e da Suíça. O resultado analítico demonstrou que 57,0\% dos TR obtiveram resultados satisfatórios e 43,0\%, resultados insatisfatórios, quando comparados aos valores de sensibilidade e especificidade declarados pelo fabricante na instrução de uso. Conclusões: Há necessidade de constante monitoramento dos TR para COVID-19, com finalidade precípua de garantir a qualidade dos produtos comercializados no país, um dos pilares das ações do Sistema Nacional de Vigilância Sanitária. 


\section{ABSTRACT}

Introduction: In December 2019, the first group of patients with symptoms of atypical pneumonia was discovered in Wuhan, China. On January 7, 2020, the etiologic agent was identified; it was a new betacoronavirus, genetically similar to SARS-CoV-1, consisting of a simple RNA strand, an enveloped virus of $50-200 \mathrm{~nm}$ in diameter, which was called SARS-CoV-2. Soon after, the disease was named COVID-19. On January 30, WHO declared a Public Health Emergency of International Importance due to the spread of the coronavirus. Tests for serological detection of IgM and IgG antibodies are those that provide an estimate of the immune response to SARS-CoV-2, highlighting the Rapid Diagnostic Tests (RDT), simple and accessible with a result within 5-30 minutes, based on sensitization of antigens/antibodies conjugated to colloidal gold capturing specific proteins present in the infected serum, plasma or blood. Objective: This work aims to show the analysis carried out with RDT for COVID-19 diagnosis in compliance with the current legislation from 02.04 to 18.08.2020. Method: In March of 2020, 25 serum/plasma samples were donated, without any identification. These samples were the remaining samples of tests performed on individuals with a confirmed diagnosis of SARS-CoV-2 infection by the RT-PCR technique from health services (National Institute of Infectious Diseases Evandro Chagas - INI and State Institute of the Brain Paulo Niemeyer - IEC) located in the metropolitan region of the state of Rio de Janeiro. The samples obtained in order to become a serological panel were stored at $-20^{\circ} \mathrm{C}$ until the moment of use. Simultaneously, a panel of samples with confirmed reactivity for IgM and IgG antibodies from COVID-19 was being made, throughout the pandemic and the samples used were evaluated against three Rapid Tests, of different antigenic compositions or different brands; two ELISA tests for IgM and IgG; two chemiluminescence tests and when applicable, a molecular test. In order to assess the specificity of the products sent, surplus donation plasma samples were selected, known to be negative for HIV, HTLV, hepatitis b and c, chagas and syphilis, collected between 2013 and 2014, in the southern regions of the country, period in which SARS-CoV-2 was nonexistent in the world. In addition to True Positive (VP) and True Negative (VN) samples, interfering serum or plasma samples with reactivity for HIV, HCV, HTLV, HBsAg, chagas disease, syphilis and dengue were also included in the evaluation. Results: Out of 178 TR lots, 74.1\%, 132 lots were from China and 25.9\%, 46 TR lots were from Brazil; Germany; South Korea; Canada; USA; Singapore; Ireland and Switzerland. The analytical result showed that 57.0\%, 101 TR lots obtained a Satisfactory result and 43\%, 77 lots had Unsatisfactory results, when compared to the Sensitivity and Specificity values declared by the manufacturer, in the Instructions for Use. Conclusions: The results obtained show the need for constant monitoring of TRs for COVID-19 with the primary purpose of guaranteeing the quality of products sold in the country, one of the National Health Surveillance System pillars of action.

KEYWORDS: COVID-19; SARS-CoV-2; Rapid Diagnostic Test; Quality Monitoring

\section{INTRODUÇÃOO}

Em dezembro de 2019, foi descoberto, na província de Hubei, cidade de Wuhan, China, o primeiro grupo de pacientes com sintomas de uma pneumonia atípica não identificada etiologicamente $^{1,2}$. Em 7 de janeiro de 2020 o agente etiológico foi identificado: tratava-se de um novo betacoronavírus, geneticamente similar ao SARS-CoV-1, constituído de fita simples de RNA, vírus envelopado de 50-200 nm de diâmetro, designado como SARS-CoV-2 e a doença foi denominada COVID-19². A doença disseminou-se rapidamente alcançando mais de 150 países em três meses, inicialmente pelo continente asiático, havendo relatos na Tailândia, Japão e Coreia do Sul nos dias 13, 15 e 20 de janeiro, respectivamente, e, em seguida, em outros países e continentes ${ }^{3}$.

Em 22 de janeiro de 2020, foi discutido por um comitê de emergência organizado pela Organização Mundial da Saúde (OMS) se esse evento se constituía ou não de uma Emergência de Saúde Pública de Âmbito Internacional (PHEIC). Essa situação representa uma declaração formal da OMS de "um evento extraordinário, que acarreta implicações para a saúde pública além da fronteira do estado afetado, através da propagação internacional de doenças e pode exigir uma resposta internacional imediata e coordenada" ${ }^{4}$.

Na sequência, em 30 de janeiro, a OMS declarou, após reunião com especialistas, a ocorrência de uma PHEIC em razão da disseminação do coronavírus ${ }^{4}$. Em 11 de março, devido à ocorrência de mais de 118.000 casos da doença distribuídos em mais de 110 países e territórios, ao redor do mundo, foi declarada a pandemia. Isto ocorre, de acordo a OMS, quando uma doença tem a capacidade de infectar pessoas facilmente, de se espalhar de pessoa para pessoa, de forma eficiente e sustentada, em várias regiões ${ }^{4,5,6}$.

Segundo a OMS, em 19 de fevereiro de 2021, às 12 h 05 min, existiam no mundo 109.594.835 casos confirmados de COVID-19 e 2.424.060 óbitos registrados ${ }^{7}$. No Brasil, segundo dados do Ministério da Saúde, em 6 de fevereiro de 2021, às 18 h 30 min, após praticamente 12 meses do registro do primeiro caso ocorrido em 26 de fevereiro de 2020 em São Paulo, o país contava com 9.497.795 casos confirmados e 231.012 óbitos $^{8}$. O maior registro de novos casos (87.843 casos) ocorreu no dia 7 de janeiro de 2021 e o de óbitos (1.595 óbitos), em 29 de julho de $2021^{8}$. A Região Sudeste era a região com maior incidência de novos casos (135.053) e a maior taxa de mortalidade no país era a da Região Norte, com o estado do Amazonas apresentando 212,3 óbitos/100 mil habitantes ${ }^{8}$.

O SARS-CoV-2 pertence à linhagem B da família do beta-coronavírus, de origem zoonótica, geneticamente similar ao coronavírus de 2002 (SARS-CoV-1), ${ }^{2}$ constituído de fita simples de RNA, vírus envelopado de 50-200 nm de diâmetro. Sete espécies podem infectar humanos, sendo que três podem produzir doenças graves, o SARS-CoV-2, o SARS-CoV, agente da pandemia 
de 2002-2003, e o MERS-CoV, causador da síndrome respiratória do Oriente Médio ${ }^{2,3,9}$. $O$ genoma do SARS-CoV-2 é semelhante ao do SARS-CoV-1 de morcegos e do vírus MERS-CoV ${ }^{10}$, composto por cinco proteínas: spike $(\mathrm{S})$, proteína do nucleocapsídeo $(\mathrm{N})$, dímero da proteína da hemaglutinia esterase $(\mathrm{HE})$, proteína do envelope $(E)$ e proteína de membrana9,10,12.

A doença pode ser transmitida de humano a humano e possui um período médio de incubação de aproximadamente cinco dias (variando de dois a 14 dias), com aparecimento de sintomas em aproximados 12 dias após a infecção (variando de oito a 16 dias) $)^{10,11,13}$, entretanto há casos na literatura com período de incubação superior a 19 dias $^{9,11,13}$.

A transmissão pode ocorrer antes que os indivíduos possivelmente infectados desenvolvam sintomas, sendo considerados indivíduos pré-sintomáticos. Além disso, uma parcela de indivíduos infectados, que nunca irão desenvolver sintomas específicos da infecção, poderá contribuir de forma significativa, para a transmissão da doença ${ }^{11}$.

\section{Diagnóstico laboratorial}

A partir de 1970, dentre as diferentes metodologias desenvolvidas e aplicáveis ao diagnóstico de doenças, se destacam: o teste molecular para detecção de ácido nucléico em tempo real (Nucleic Acid Amplification Technology - NAT) que foi desenvolvido em 1988, por Kary Mullis, considerado como padrão ouro principalmente no caso da COVID-19, e os testes sorológicos, desenvolvidos a partir de 1971 por Peter Perlmann e Eva Engwell ${ }^{13}$.

Embora a detecção de RNA viral baseada em reverse-transcriptase polymerase chain reaction (RT-PCR) tenha sido amplamente utilizada no diagnóstico de COVID-19, ela não pode ser aplicada ao monitoramento do progresso dos estágios da doença ou avaliação da imunidade ${ }^{13,14,15}$.

Os testes sorológicos, como testes complementares aos moleculares, são baseados na detecção de anticorpos lgM e lgG que podem fornecer uma estimativa da resposta imune ao SARS-CoV-2 na população ${ }^{11,15}$. Existem quatro tipos de testes sorológicos: os testes rápidos (rapid diagnostics tests), que são imunocromatográficos; os ensaios de imunoabsorção enzimática (enzyme linked immunosorbent assay - ELISA); os de quimioluminescência (chemiluminescence immunoassay - CLIA) e os ensaios de neutralização, este último deve ser realizado em laboratórios de maior complexidade e requer de três a cinco dias para obtenção dos resultados ${ }^{11,15}$.

Dentre os testes de simples execução e acessibilidade, o teste rápido, tipicamente qualitativo (positivo ou negativo), cujo resultado pode ser obtido entre 5-30 min, baseia-se na sensibilização de antígenos/anticorpos conjugados ao ouro coloidal que capturam imunoglobulinas e proteínas específicas do SARS-CoV-2 presentes no soro, plasma ou sangue dos indivíduos infectados, formando um complexo antígeno-anticorpo que migra por capilaridade ao longo da membrana de nitrocelulose $\mathrm{e}^{11,13,16}$. A membrana de nitrocelulose é disposta em um dispositivo de polietileno, vulgarmente denominado dispositivo teste ou cassete ${ }^{11,16}$.
Como o resultado da imunocromatografia, os complexos entre antígenos e anticorpos são capturados pelos anticorpos anti-humanos IgM e/ou IgG fixados à tira de nitrocelulose para formação da linha teste $(T)$. 0 marcador (ouro coloidal) se liga especificamente à área destinada ao controle da reação para formação da linha controle $(C)^{11,16}$, conforme demonstrado na Figura 1.

A detecção de anticorpos é indicada por linhas visíveis, que aparecem na tira de teste, ou por fluorescência, que pode ser identificada usando um dispositivo de leitura. Muitos desses testes são conhecidos como imunoensaios baseados em ouro coloidal, pois usam o antígeno do vírus conjugado a nanopartículas de ouro ${ }^{17,18}$. No caso do SARS-CoV-2, ainda não está totalmente determinada a soroconversão da fase aguda da infecção, no entanto já foram detectados anticorpos IgA e IgM no $5^{\circ}$ dia de sintomas com intervalo interquartil de 3 a 6 dias, respectivamente, e, quanto aos anticorpos IgG anti-SARS-CoV-2, o tempo médio de aparecimento foi no $14^{\circ}$ dia da infecção, com intervalo interquartil de 10 a 18 dias $^{16,18,19,20,21}$ (Figura 2).

Em qualquer surto de doença infecciosa, um teste de diagnóstico preciso e acessível deve ser um dos pilares das políticas de medidas de controle sanitário para compreender e minimizar a propagação de doenças ${ }^{1}$. Nesse contexto, o Instituto Nacional de Controle de Qualidade em Saúde (INCQS), pertencente à Fundação Oswaldo Cruz (Fiocruz) e tecnicamente subordinado à Agência Nacional de Vigilância Sanitária (Anvisa), atua como referência para as questões científicas e tecnológicas relativas ao controle de qualidade de produtos, ambientes e serviços vinculados à Vigilância Sanitária.

Esse instituto, por meio do Laboratório de Sangue e Hemoderivados, vem desde o ano de 2000 avaliando rotineiramente por análise prévia, fiscal e de controle, conforme previsto em legislação, os produtos para diagnóstico de uso in vitro pertencentes a classe de risco IV e, mais recentemente, classe de risco III, diferentes metodologias e marcadores, com vistas à avaliação da qualidade dos produtos pré e pós-mercado.

Ainda segundo a legislação vigente, Lei $n^{\circ} 5.991$, de 17 de dezembro de 1973, e da Lei ${ }^{\circ} 6.360$, de 23 de setembro de 1977 , as análises previstas estão assim definidas: prévia - efetuada em determinados produtos sob regime de vigilância sanitária, a fim de ser verificado se os mesmos podem ser objeto de registro; controle - efetuada em produtos sob o regime de vigilância sanitária, após sua liberação ao consumo, e destinada a comprovar a conformidade do produto segundo as especificações estabelecidas por ocasião da solicitação do registro; e fiscal - efetuada sobre os produtos submetidos ao sistema instituído pela legislação, em caráter de rotina, para apuração de infração ou verificação de ocorrência fortuita ou eventual ${ }^{22,23,24,25}$.

Atualmente, as diretrizes para o registro dos kits para diagnóstico estão fundamentadas na Resolução da Diretoria Colegiada (RDC) $n^{\circ} 36$, de 26 de agosto de 2015, que tem por objetivo estabelecer a classificação de risco, o regime de controle, cadastro e registro e os requisitos de rotulagem e instruções de uso de produtos para diagnóstico in vitro, inclusive seus instrumentos ${ }^{25}$. 


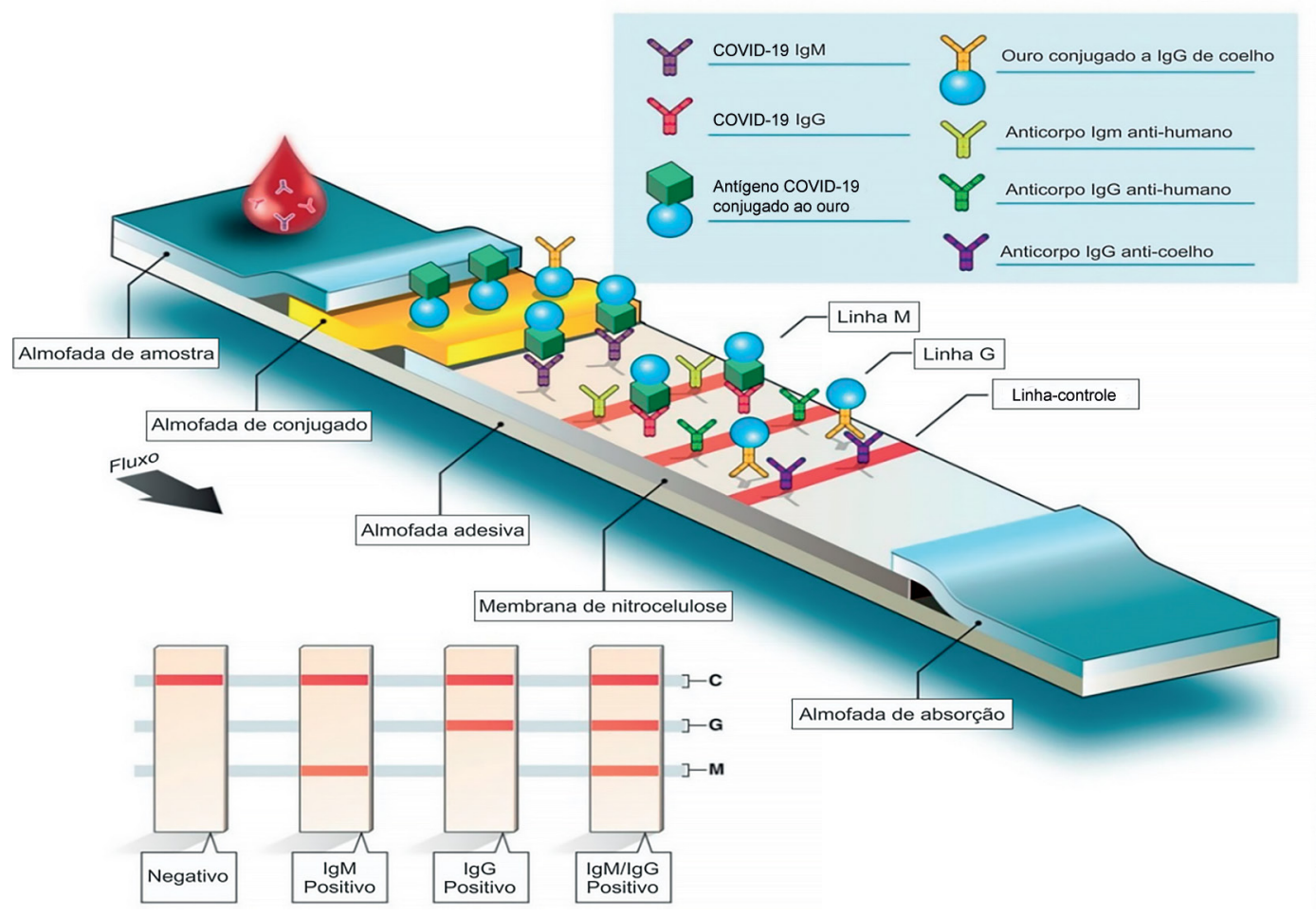

Fonte: Adaptado ${ }^{1}$

Figura 1. Esquema da confecção do teste rápido.

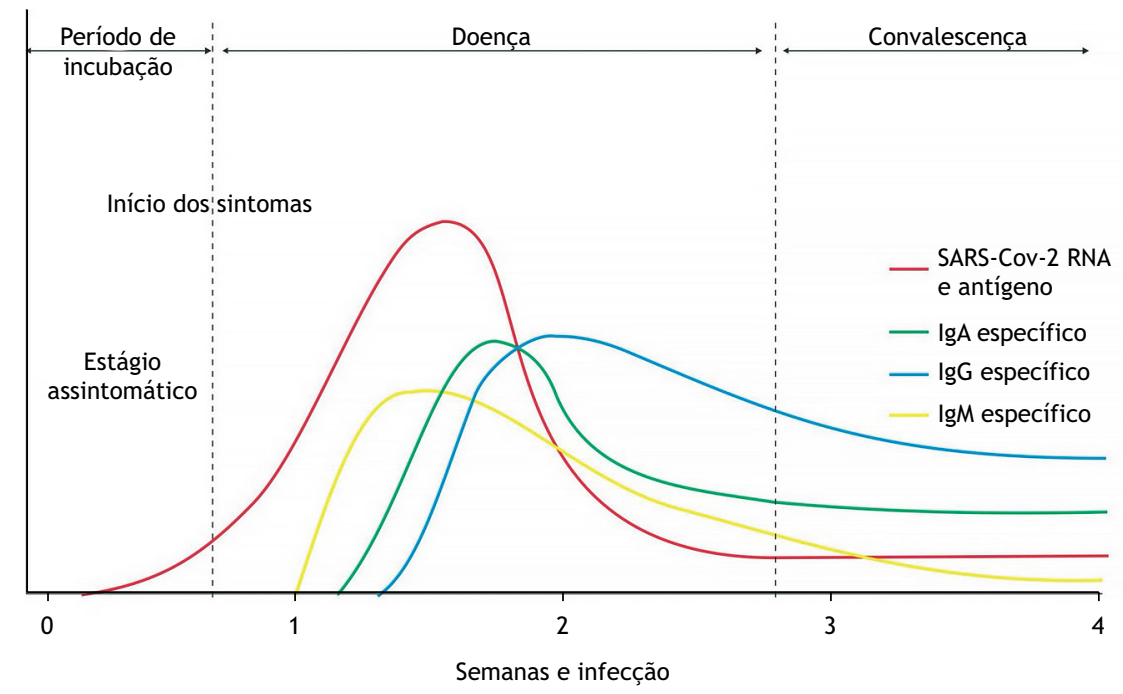

Fonte: Adaptado ${ }^{1}$

Figura 2. Esquema do curso da soroconversão após infecção pelo SARS-CoV-2.

Com a declaração da pandemia de COVID-19 pela OMS e a necessidade de disponibilizar testes para diagnóstico do SARS-CoV-2 no mercado nacional, a Coordenação Geral de Análise das Contratações de Insumos Estratégicos para Saúde do Ministério da Saúde publicou, em 17 de março de 2020, o aviso de chamamento público que teve por objetivo convocar as empresas a fornecerem os portfólios dos insumos para diagnóstico da COVID-19 à
Coordenação Geral de Laboratórios de Saúde Pública (CGLAB) do Ministério da Saúde ${ }^{26}$. Este aviso cadastrou cerca de 20 empresas para apresentar seus produtos para análise controle.

Na sequência, a Anvisa publicou a RDC $n^{\circ} 379$, de 30 de abril de $2020^{27}$, que alterou a RDC $n^{\circ} 356$, de 23 de março de 2020 , atualmente revogada, que dispõe, de forma extraordinária e temporária, sobre os requisitos para fabricação, importação 
e aquisição de dispositivos médicos prioritários para o uso em serviços de saúde, em virtude da emergência de saúde pública internacional, identificados como relacionados ao SARS-CoV-2. Essa RDC, em seu inciso $7^{\circ}$ do art. $9^{\circ}$, estabelece que:

Os responsáveis pelas importações de kits para diagnóstico nos termos do caput devem enviar em um prazo máximo de 5 (cinco) dias, contados da data do desembaraço da carga, uma amostra de, no mínimo, 100 unidades de cada lote importado para análise do Instituto Nacional de Controle de Qualidade - INCQS ${ }^{28}$.

Desta forma, este trabalho teve como objetivo apresentar a análise efetuada nos testes rápidos (imunocromatográficos) para diagnóstico da COVID-19 recebidos para análise, conforme determinado no aviso de chamamento público do Ministério da Saúde e atendimento à $\operatorname{RDC} n^{\circ} 379 / 2020$, no período de 2 de abril de 2020 a 18 de agosto de 2020 .

\section{MÉTODO}

Em atendimento ao art. $9^{\circ}$ da RDC $n^{\circ} 379 / 2020$, no período de 2 de abril de 2020 a 18 de agosto de 2020, foram recebidos, para análise, no INCQS, 277 lotes de kits de diagnóstico da COVID-19, com amostragem de 100 testes para cada lote de diferentes metodologias como: testes rápidos (TR), ELISA, quimioluminescência e RT-PCR. Neste trabalho foram considerados apenas os TR destinados à detecção de anticorpos IgM e IgG, para COVID-19, embora o laboratório tenha também recebido os TR para detecção de antígenos e para amplificação isotérmica de ácidos nucleicos, totalizando 178 lotes de TR avaliados para os atributos de sensibilidade e especificidade, assim como o desempenho técnico dos cassetes ou dispositivos-teste, ferramenta que contempla a tira de nitrocelulose destinada aos testes ${ }^{26}$.

Os kits, de acordo com o $\S 7^{\circ}$ da RDC $n^{\circ} 379 / 2020$, foram recebidos acompanhados do certificado de liberação do lote emitido pelo controle da qualidade; cópia do Anexo I, Termo de Responsabilidade conforme previsto na legislação; dossiê completo de produção e controle de qualidade, enfatizando o teste de estabilidade, além das instruções de uso em língua portuguesa, previsto no $\S 5^{\circ}$ do art. $9^{\circ}$ da mesma $\mathrm{RDC}^{26}$.

Durante o mês de março, foram gentilmente cedidas 25 amostras de soro/plasma excedentes da realização de testes efetuados em indivíduos com diagnóstico confirmado de infecção pelo SARS-CoV-2 pela técnica de RT-PCR provenientes de serviços de saúde (Instituto Nacional de Infectologia Evandro Chagas - INI e Instituto Estadual do Cérebro Paulo Niemeyer - IEC) localizados na região metropolitana do estado do Rio de Janeiro. As amostras obtidas para a confecção de painel sorológico foram armazenadas a $-20^{\circ} \mathrm{C}$ até o momento do uso.

Além disso, um painel de amostras com reatividade confirmada para anticorpos IgM e IgG para a COVID-19 foi sendo confeccionado, ao longo da pandemia, e as amostras utilizadas foram avaliadas frente a, no mínimo, três TR de diferentes composições antigênicas ou diferentes marcas; dois testes ELISA para IgM e IgG; dois testes de quimioluminescência e, quando aplicável, um teste molecular.
Para avaliação da especificidade dos produtos encaminhados, foram selecionadas amostras de plasma excedentes de doação, sabidamente negativas para: HIV, HTLV, hepatite B e C, doença de chagas e sífilis, nos anos de 2013 e 2014, período no qual o SARS-CoV-2 ainda era inexistente. Além de amostras verdadeiro positivas (VP) e verdadeiro negativas (VN), ainda foram incluídas na avaliação, amostras de soro ou plasma interferentes com reatividade para: HIV, HCV, HTLV, HBsAg, doença de chagas, sífilis e dengue.

No período de análise, ainda não havia sido disponibilizado no mercado nacional e internacional padrões e/ou painéis internacionais ou soros-padrão para COVID-19, portanto não foram incluídos neste trabalho. As análises foram realizadas seguindo estritamente as instruções de uso que acompanhavam os produtos. Os valores percentuais dos atributos de sensibilidade e especificidade obtidos nos lotes dos produtos avaliados foram comparados com os valores declarados nas instruções de uso que acompanhavam os testes rápidos. Entende-se por sensibilidade clínica o percentual de resultados positivos obtidos quando o analito está presente na amostra, reconhecendo a presença de uma determinada doença ou condição, e a especificidade clínica, como a capacidade de um método analítico determinar somente o analito frente a outras substâncias presentes na amostra analisada ${ }^{25}$. Entende-se por falso negativo o resultado negativo obtido em amostras de indivíduo infectado e por falso positivo o resultado falso positivo obtido em amostras de indivíduos não infectados ${ }^{25}$.

O valor de sensibilidade de cada produto foi obtido com base no número de amostras VP para IgM e para IgG analisadas e corretamente identificadas pelo teste avaliado. Foi calculado de acordo com a tabela de contingência $2 \times 2$, com a seguinte equação: resultados VP divididos pela soma dos resultados VP com os resultados falso negativos multiplicados por 100. A especificidade foi calculada de acordo com a seguinte equação: resultados VN divididos pela soma dos resultados VN com os resultados falso positivos multiplicados por $100^{25,28}$.

Por se tratar de uma nova infecção de caráter mundial, aliados à ausência de padrões internacionais, foram adotados como valor de referência os valores da especificação declarados pelo fabricante na instrução de uso que acompanha o produto. 0 valor de referência é definido como valor teórico ou estabelecido em princípios científicos que servem como referência para comparação com o resultado obtido. Desta forma, os testes cujos valores de sensibilidade e/ou especificidade foram superiores ou iguais aos declarados pelo fabricante, na instrução de uso, foram considerados satisfatórios e os que apresentaram valores inferiores, insatisfatórios ${ }^{25}$.

A amostragem de 100 testes por lote de produto recebido para análise foi assim distribuída para efetuar cada análise: a) amostras positivas para COVID-19 IgM e/ou IgG: $25 \%$ a $30 \%$; b) amostras negativas (amostras coletadas entre os anos de 2013 e 2014, isentas de HIV; HTLV; HCV; HBsAg; sífilis; dengue; chikungunya e zika, previamente analisadas e comprovadamente negativas, bem como amostras isentas de COVID-19, pois foram coletadas antes do $1^{\circ}$ caso confirmado no país, ocorrido em fevereiro de 2020): $60 \%$ a $65 \%$; c) amostras interferentes para HIV, HTLV, $\mathrm{HBsAg}, \mathrm{HCV}$, doença de chagas, sífilis e dengue: $5 \%$ a $10 \%$, conforme estabelecido no procedimento analítico. 
Além disso, foram identificados e quantificados desvios de qualidade quanto aos cassetes ou dispositivos testes recebidos para análise, como: a) presença de falhas na marcação da linha controle do cassete ou dispositivo teste; b) falhas na marcação da linha teste; c) tiras de nitrocelulose deslocada do visor do cassete ou dispositivo-teste; d) outros desvios de qualidade dos cassetes constatados durante os testes. Por se tratar de leitura visual e dependente da acuidade visual de cada profissional, bem como analito destrutível, a leitura dos resultados foi efetuada por mais de um profissional e fotografada, para registro.

\section{RESULTADOS E DISCUSSÃO}

Os 178 lotes recebidos para análise foram assim distribuídos: $150(84,2 \%)$ kits destinados à análise-controle; 24 (13,6\%) kits coletados pelas Vigilâncias Sanitárias estaduais e/ou municipais para análise fiscal; e quatro $(2,2 \%)$ kits destinados às amostras de perícia de contraprova. A perícia de contraprova é o recurso impetrado pela empresa, de acordo com e Lei $n^{\circ} 6.437$, de 20 de agosto de 1977 , ao discordar do resultado obtido da análise fiscal ${ }^{24}$.

As coletas destinadas à análise fiscal corresponderam aos seguintes estados: Espírito Santo, Minas Gerais, Rio de Janeiro, São Paulo, Paraná, Rio Grande do Sul, Santa Catarina e Goiás. Ao avaliar esta distribuição, 149 (83,7\%) kits recebidos corresponderam à análise-controle em atendimento ao chamamento público do Ministério da Saúde e principalmente à RDC $n^{\circ} 379 / 2020$, que tornou obrigatório para as empresas encaminhar os kits para análise durante o desembaraço alfandegário.

Outro fato que vale ressaltar correspondeu ao quantitativo de 24 $(13,5 \%)$ lotes coletados para análise fiscal e cinco $(3,0 \%)$ lotes destinados à perícia de contraprova, promovida pela Anvisa por meio do programa de monitoramento da qualidade dos kits para diagnóstico da COVID-19, uma ferramenta imprescindível ao controle de qualidade de produtos.

Dos 178 lotes de TR recebidos para análise no período supracitado, os fabricantes corresponderam a 73 empresas em três continentes: $13(17,9 \%)$ do continente americano, 55 (75,3\%) do continente asiático e cinco $(6,8 \%)$ do continente europeu. A origem dos produtos envolveu nove países no mundo e 73 empresas fabricantes assim distribuídas: $49(67,1 \%)$ empresas oriundas da China; nove $(12,3 \%)$ empresas do Brasil; cinco $(6,8 \%)$ da Coreia do Sul; três $(4,1 \%)$ da Alemanha; três $(4,1 \%)$ dos EUA; uma $(1,40 \%)$ do Canadá, da Irlanda, de Cingapura e da Suíça, respectivamente. Vale destacar as cinco cidades da China que contribuíram com a maioria das empresas que importaram kits para o diagnóstico da COVID-19: Hangzhou, sete $(33,5 \%)$ empresas; Shanghai, seis $(28,5 \%)$ empresas; Beijing, quatro $(19,0 \%)$ empresas; Guangzhou e Shenzhen, duas $(9,5 \%)$ empresas cada. Das nove empresas nacionais, quatro $(44,5 \%)$ empresas estão localizadas em São Paulo; duas (22,2\%) em Minas Gerais; duas (22,2\%) no Rio de Janeiro e uma $(11,1 \%)$ no Paraná.

Neste quesito, vale destacar a China, com 49 empresas e, dessas, 21 localizadas em cinco províncias chinesas, ratificando o país, como tigre asiático no comércio de produtos, dentre esses,
TR destinados ao diagnóstico da COVID-19. Outro destaque é o Brasil, que neste trabalho foi representado com nove empresas, demonstrando o parque fabril instalado no país, assim como a necessidade de fabricar e distribuir produtos nacionais, destinados à população brasileira.

Quanto à distribuição da procedência dos 178 lotes de kits de TR para COVID-19 recebidos para análise: $132(74,1 \%)$ lotes foram oriundos da China e 46 (25,9\%) corresponderam aos demais países como: Brasil, com $16(9,0 \%)$ lotes; Alemanha, com nove $(6,2 \%)$; Coreia do Sul, com nove $(5,0 \%)$; Canadá, com quatro $(2,20 \%)$; EUA, com três $(1,7 \%)$, Cingapura, Irlanda e Suíça, um $(0,6 \%)$ por país. É evidenciada a forte participação da China como também do Brasil. Além disso, foram evidenciadas 122 empresas importadoras ou distribuidoras no país ou requerentes públicos de análise, para comercializar os 178 lotes de TR para COVID-19: 94 (77,0\%) comercializaram os produtos provenientes da China; nove $(7,4 \%)$ comercializaram os produtos nacionais; sete $(5,7 \%)$ comercializaram os produtos provenientes da Coreia do Sul; três (2,5\%), os produtos da Alemanha, EUA e Canadá e uma $(0,8 \%)$, os produtos provenientes da Irlanda, Cingapura e Suíça. O destaque mais uma vez vai para a China com 94 empresas que importaram e comercializaram seus produtos no país, como mostra a Figura 3.

Ao avaliar o quantitativo de lotes de kits recebidos no período de 2 de abril a 18 de agosto, foi verificado que 75 (42,1\%) lotes foram recebidos no mês de junho, seguido por $65(36,5 \%)$ lotes em julho; $16(9,0 \%)$ lotes em agosto; $14(7,9 \%)$ lotes em maio e oito $(4,5 \%)$ lotes em abril, no início das análises.

Quanto à modalidade de análise, foram recebidas amostras sob três modalidades: análise de controle, análise fiscal e análise de perícia de contraprova ${ }^{23,24}$.

A análise de perícia de contraprova é previamente agendada com a Anvisa e a Vigilância Sanitária que coletou o produto. Na sequência, a empresa é notificada e a análise é efetuada de acordo com o seguinte rito preconizado pela legislação vigente: procedimento analítico estritamente semelhante ao efetuado na análise fiscal e elaboração de ata contendo todas as informações pertinentes a esta atividade, frente aos representantes indicados pela empresa, para presenciar esta perícia ${ }^{24}$. 0 resultado da perícia de contraprova segue diretamente para a Vigilância Sanitária local e a Anvisa, para as providências administrativas e sanitárias cabíveis ${ }^{25}$.

Os 178 lotes encaminhados para análise foram assim distribuídos: $149(84 \%)$ lotes destinados à análise-controle, em atendimento ao chamamento público do Ministério da Saúde e à RDC $\mathrm{n}^{\circ}$ 379/2020; 24 (19\%) lotes coletados para análise fiscal, em atendimento à Lei $n^{\circ} 6.437 / 1977$ e cinco (3\%) lotes destinados à perícia de contraprova ${ }^{23,24,26}$ (Figura 4A).

A sensibilização da fase sólida do teste, tira de nitrocelulose, foi assim realizada: 100 (56,3\%) lotes de TR foram sensibilizados com anticorpos anti-IgM/IgG humanos, seguidos por 36 (20,2\%) lotes sensibilizados com anticorpos monoclonais anti-lgM/ 


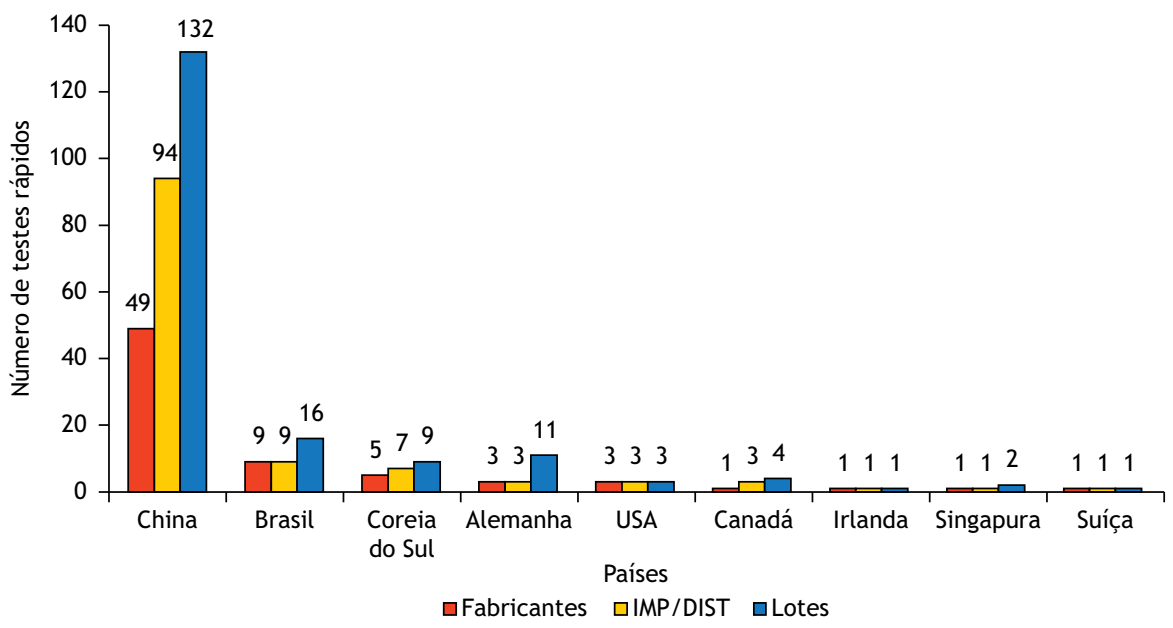

Fonte: Laboratório de Sangue Hemoderivados, 2020.

IMP: importadores; DIST: distribuidoras.

Figura 3. Demonstrativo da importação e/ou comercialização dos testes rápidos para COVID-19.

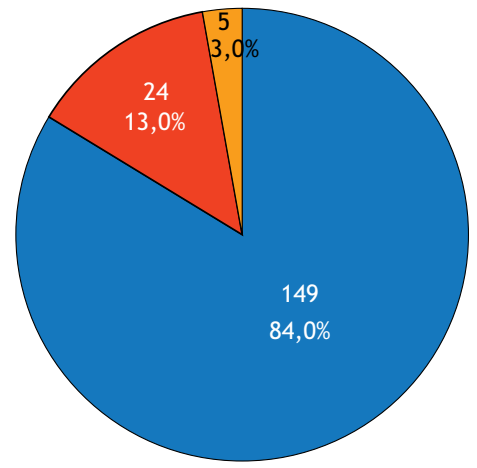

$\square$ Controle $\quad \square$ Fiscal $\quad \square$ Contraprova

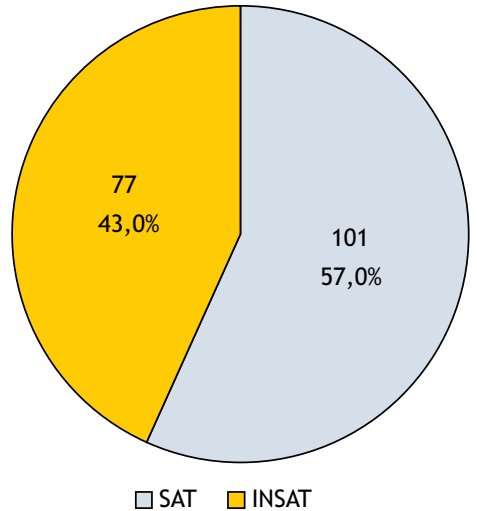

C

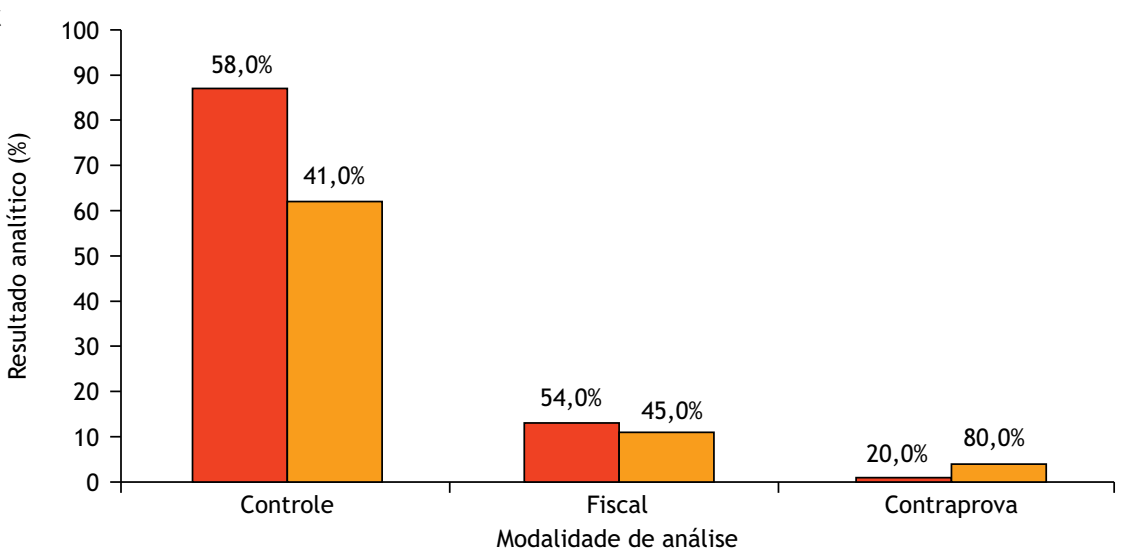

$\square$ Satisfatória

$\square$ Insatisfatória

Fonte: Laboratório de Sangue e Hemoderivados, 2020.

Figura 4. Distribuição da modalidade de análise e resultados obtidos. (A) Distribuição das amostras recebidas por modalidade de análise; (B) Resultados analíticos obtidos; (C) Resultado analítico por modalidade de análise.

IgG; $33(18,5 \%)$ sensibilizados com antígeno recombinante do SARS-CoV-2 e nove $(5,0 \%)$ lotes com proteínas recombinantes específicas do SARS-CoV-2.
Quanto às instruções de uso, $142(80,0 \%)$ lotes de produtos foram traduzidos para o português e $36(20,0 \%)$ ainda permaneciam em inglês. No entanto, vale destacar que a tradução para 
o português, na maioria das instruções de uso foi realizada de forma precária, dificultando o entendimento do procedimento e o desempenho dos produtos. Uma rígida análise das instruções de uso será objeto de um artigo específico.

A matriz de análise também foi avaliada. Dos 178 lotes de produtos analisados, $165(92,7 \%)$ declararam como matriz de análise, na instrução de uso, soro ou plasma ou sangue por punção digital e $13(7,3 \%)$ apenas aceitam soro e plasma humano.

Dos 178 lotes recebidos para análise, foram executados 17.800 testes. Destes, em aproximadamente 4.900 testes foram utilizadas amostras positivas e em 12.900 testes, amostras negativas e interferentes. Entre esses 178 lotes de TR recebidos para análise, cinco $(2,8 \%)$ corresponderam aos kits vinculados a equipamentos de leitura das tiras, que têm por finalidade dirimir o viés da leitura visual dos testes, e $173(97,2 \%)$ mantiveram a leitura visual.

$\mathrm{Na}$ análise de desempenho técnico dos cassetes, foram abordados os defeitos constatados durante a análise e, nesse caso, foram excluídos 500 testes referentes aos cassetes com leitura por equipamentos. Portanto, nessa avaliação, a amostragem foi efetuada em 17.300 testes e em aproximadamente 12.543 testes foram utilizadas amostras negativas e em 4.757 testes foram utilizadas amostras positivas.

Dos 17.300 cassetes analisados, 13.512 cassetes não apresentaram defeitos e 3.788 cassetes apresentaram defeitos como: 125 inválidos; 133 manchados; 37 com as tiras deslocadas do visor; 815 com falhas na marcação da linha-controle; 394 com marcação da linha-controle muito fraca, quase imperceptível; 2.284 com marcação da linha-teste para COVID-19 IgM ou IgG muito fraca, quase imperceptível. As marcações da linha-teste muito fracas implicam no aparecimento de resultados falso negativos e tais defeitos encontrados ratificam o resultado analítico final.

Entre os 178 lotes de TR analisados, foram obtidos os seguintes resultados: 101 (57,0\%) lotes obtiveram resultado satisfatório e $77(43,0 \%)$ obtiveram resultados insatisfatórios, quando os resultados foram comparados com os valores atribuídos para os atributos de sensibilidade e especificidade declarados pelo fabricante, na instrução de uso (Figura 4B).

Ao avaliar o resultado analítico frente as diferentes modalidades de análise, foram observados os seguintes resultados: dos 149 lotes de análise controle, $87(58,3 \%)$ obtiveram resultados satisfatórios e $62(41,7 \%)$, insatisfatórios. Quanto à análise fiscal, foram analisados 24 lotes, com os seguintes resultados: $13(54,2 \%)$ obtiveram resultados satisfatórios e $11(45,8 \%)$, insatisfatórios. Os resultados insatisfatórios obtidos em amostras coletadas para análise fiscal implicam no recurso de perícia de contraprova, impetrado pela empresa importadora ou distribuidora, por isso, cinco $(2,80 \%)$ amostras foram objeto da perícia de contraprova e obtiveram os seguintes resultados: uma $(20,0 \%)$ amostra foi considerada satisfatória e quatro $(80,0 \%)$ amostras obtiveram resultado insatisfatório, quando comparado aos valores declarados, pelo fabricante, para sensibilidade e especificidade, na instrução de uso (Figura 4C).
O resultado analítico satisfatório na análise de perícia de contraprova correspondeu à empresa que submeteu uma alteração das informações do dossiê técnico à Gerência de Produtos para Diagnóstico da Gerência-Geral de Tecnologia e Produtos para a Saúde da Anvisa para apresentar novos estudos de desempenho do produto, aumentando o tamanho amostral, apresentando novos valores para os atributos de sensibilidade e especificidade e, ainda, incluindo o intervalo de confiança de $95 \%$.

Esta alteração dos valores de sensibilidade e especificidade declarados na instrução de uso proporcionou a aprovação dos resultados quando comparados aos valores atualizados. Os produtos que obtiveram resultados insatisfatórios, na perícia de contraprova, foram diretamente encaminhados às Vigilâncias Sanitárias que coletaram as amostras e para a Anvisa, a fim de que fossem tomadas as providências cabíveis, previstas na Lei $n^{\circ}$ $6.437 / 1977$. Cumpre destacar que estas ações são os pilares da Vigilância Sanitária de produtos.

Dos resultados satisfatórios dos atributos de sensibilidade e especificidade, foi verificada a distribuição da frequência dos valores obtidos assim agrupados:

1. Sensibilidade: $69(68,3 \%)$ resultados na faixa de $80 \%$ a $95 \%$; $27(26,7 \%)$ resultados na faixa de $95,1 \%$ a $99,9 \%$ e cinco $(5,0 \%)$ em $100 \%$;

2. Especificidade: cinco $(5,0 \%)$ resultados na faixa de $80 \%$ a $95 \%$; $72(71,3 \%)$ na faixa de $95,1 \%$ a $99,9 \%$ e $24(23,7 \%)$ em $100 \%$.

Ao observar estes resultados, é possível inferir que a faixa do atributo sensibilidade foi de $80 \%$ a $95 \%$, representado por 69 resultados dos TR analisados. Tal percentual implica principalmente com o tipo de sensibilização da fase sólida do produto, bem como com o período de soroconversão, ainda não totalmente definido.

Ao analisar a especificidade, como foram encontrados $72(71,3 \%)$ TR com resultados na faixa de $95,1 \%$ a $99,9 \%$, além de $24(23,7 \%)$ com $100 \%$ de especificidade, podemos observar nessa amostragem que os produtos analisados foram mais específicos do que sensíveis ${ }^{29}$.

Os resultados insatisfatórios representaram 77 (43,0\%) lotes de TR, que demonstraram: $32(42,0 \%)$ lotes insatisfatórios para sensibilidade; $14(18,0 \%)$ lotes com resultado insatisfatório para especificidade e $32(40,0 \%)$ lotes insatisfatórios para sensibilidade e especificidade. Estes resultados se justificam quando comparados aos defeitos técnicos dos cassetes encontrados durante a análise, como, por exemplo, marcação da linha teste muito fraca, implicando em resultados falso negativos (Figura 5).

\section{CONCLUSÕES}

Os TR, por sua aplicabilidade, simplicidade e abrangência, são ferramentas amplamente utilizadas no diagnóstico sorológico da COVID-19. No entanto, na aquisição de tais produtos, a especificação dos parâmetros de sensibilidade e a 


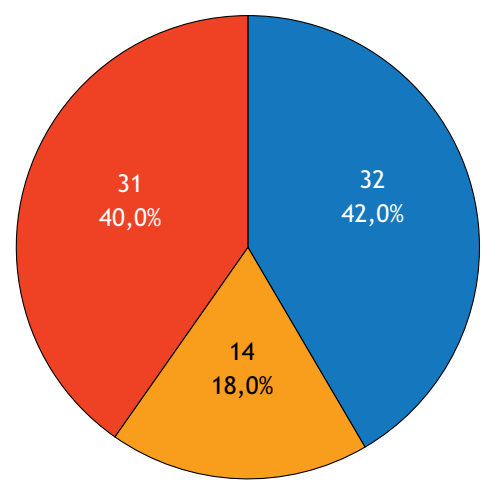

$\square$ Sensibilidade $\square$ Especificidade $\square$ Sens/Espec

Fonte: Laboratório de Sangue e Hemoderivados, 2020.

Sens: sensibilidade; Espec: especificidade.

Figura 5. Distribuição dos resultados analíticos insatisfatórios.

especificidade declaradas nas instruções de uso ainda fundamentam o mercado nacional e internacional. Objetivando controlar a qualidade dos produtos oferecidos no mercado nacional, foram avaliados os parâmetros de sensibilidade e especificidade diagnóstica dos TR empregados no diagnóstico sorológico da COVID-19, como parte do processo de importação, por excepcionalidade, em atendimento à RDC $n^{\circ}$ 379/2020. Dos 178 TR recebidos para análise, 101 apresentaram resultados satisfatórios para os parâmetros de sensibilidade e especificidade quando comparados à especificação declarada na instrução de uso que acompanha o produto. Os TR que obtiveram resultados insatisfatórios não foram distribuídos no mercado nacional.

Diante dos resultados analíticos obtidos, fica evidente a necessidade do constante monitoramento da qualidade dos produtos para diagnóstico da COVID-19, com a finalidade precípua de garantir a qualidade dos produtos comercializados no país, um dos pilares das ações do Sistema Nacional de Vigilância Sanitária, e uma contribuição para a saúde pública do país, durante o enfrentamento de uma pandemia.

\section{REFERÊNCIAS}

1. Ghaffari A, Meurant R, Ardakani A. COVID-19 serological tests: how well do they actually perform? Diagnostics. 2020;10(7):1-14. https://doi.org/103390/diagnostics10070453

2. Cevik M, Bamford CGG, Ho A. COVID-19 pandemic: a focused review for clinicians. Clin Microbiol Infect. 2020;26(7):842-47. https://doi.org/10.1016/j.cmi.2020.04.023

3. Brito SBP, Braga IO, Cunha CC, Palácio MAV, Takenami I. Pandemia da COVID-19: o maior desafio do século XXI. Vigil Sanit Debate. 2020;8(2):54-63. https://doi.org/10.22239/2317-269x.01531

4. World Health Organization - WHO. Timeline: WHO's COVID-19 response. Geneva; World Health Organization: 2020[acesso 26 ago 2020]. Disponível em: https: / /www.who.int

5. Ministério as Saúde (BR). Boletim epidemiológico especial 33: doença pelo coronavírus COVID-19. Brasília: Ministério da Saúde; 2020[acesso 20 ago 2020]. Disponível em: https://www.localizasus.saude.gov.br

6. Fundação Oswaldo Cruz - Fiocruz. Plano de contingencia da Fiocruz diante da pandemia da doença pelo SARS-CoV-2 (COVID-19) versão 1.1. Rio de Janeiro: Fundação Oswaldo Cruz; 2020.

7. World Health Organization - WHO. WHO coronavirus disease (COVID-19) dashboard. Geneva: World Health Organization; 2021 [acesso 19 fev 2021]. Disponível em: https://covid19.who.int

8. Ministério as Saúde (BR). Boletim epidemiológico especial 50: semana epidemiológica versão 2. Brasília: Ministério da Saúde; 2021[acesso 19 fev 2021]. Disponível em: https: // www.localizasus.saude.gov.br

9. Zhai P, Dind Y, Wu X, Long J, Zhong Y, Li Y. The epidemiology, diagnosis and treatment of COVID-19. Int J Antimicrob Agents. 2020;55(5):1-13. https://doi.org/10.1016/j.ijantimicag.2020.105955
10. Kakodkar P, Kaka N, Baig MN. A comprehensive literature review on the clinical presentation and management of the pandemic coronavirus disease 2019 (COVID-19). Cureus. 2020;12(4):1-18. https://doi.org/10.7759/cureus.7560

11. Neeraja R, Cortade DL, Ng E, Wang SX. Diagnostics for SARS-CoV-2 detection: a comprehensive review of the FDA-EUA COVID-19 testing landscape. Biosens Bioelectron. 2020;165:1-13. https://doi.org/10.1016/j.bios.2020.112454

12. Weissleder R, Lee R, Ko J, Pittet MJ. COVID-19 diagnostics in context. Sci Trans Med. 2020;12(546):1-5. https://doi.org/10.1126/scitranslmed.abc1931

13. Pan Y, Li X, Yang G, Fan G, Tang Y, Zhao $Y$ et al. Serological immunochromatography approach in diagnosis with SARS-CoV-2 infected COVID-19 patients. J Infect. 2020;81(1):e28-e32. https://doi.org/10.1016/j.jinf.2020.03.051

14. Carter LJ, Garner LV, Smoot JW, Li Y, Zhou Q, Saveson $\mathrm{CJ}$ et al. Assay techniques and test development for COVID-19 diagnosis. ACS Cent Sci. 2020;6(5):591-605. https://doi.org/10.1021/acscentsci.0c00501

15. Tang YW, Schmitz E, Persing DH, Stratton CW. Laboratory diagnosis of COVID-19: current issues and challenges. J Clin Microbiol. 2020;58(6):1-9. https://doi.org/10.1128/JCM.00512-20

16. Shen $B$, Zheng $Y$, Zhang $X$, Zhang $W$, Wang $D$, Jin $J$ et al. Clinical evaluation of a rapid colloidal gold immunochromatograph assay for SARS-Cov-2 IgM/lgG. Am J Transl Res. 2020;12(4):1348-54.

17. Deeks JJ, Dinnes J, Takwoingi Y, Davenport C, Spijker R, Taylor-Phillips $S$ et al. Antibody tests for identification of current and past infection with SARS-CoV-2. Cochrane Database Syst Rev. 2020;6(6):1-306. https://doi.org/10.1002/14651858 
18. To KKW, Tsang OTY, Leung WS,Tam AR, Wu TS, Lung DC et al. Temporal profiles of viral load in posterior oropharyngeal saliva samples and serum antibody responses during infection by SARS-CoV-2: an observational cohort study. Lancet Infect Dis. 2020;20(5):565-74. https://doi.org/10.1016/S1473-3099(20)30196-1

19. Guo L, Ren L, Yang S, Xiao M, Chang D, Yang $F$ et al. Profiling early humoral response to diagnose novel coronavirus disease (COVID-19). Clin Infect Dis. 2020:71(15):778-85. https://doi.org/10.1093/cid/ciaa310

20. Lerner $A M$, Eisinger RW, Lowy DR, Petersen LR, Humes R, Hepburn $M$ et al. The COVID-19 serology studies workshop: recommendations and challenges. Immunity. 2020;53(1):1-5. https://doi.org/10.1016/j.immuni.2020.06.012

21. Liu C, Mao B, Martinez V, Chen X, Li Y, He L et al. A facile assay for rapid detection of COVID-19 antibodies. Rsc Adv. 2020;10(47):28041-8. https://doi.org/10.1039/d0ra04107f

22. Brasil. Lei № 5.991, de 17 de dezembro de 1973. Dispõe sobre o controle sanitário do comércio de drogas, medicamentos, insumos farmacêuticos e correlatos, e dá outras providências. Diário Oficial União. 19 dez 1973.

23. Brasil. Lei № 6.360, de 23 de setembro de 1976. Dispõe sobre a vigilância sanitária a que ficam sujeitos os medicamentos, as drogas, os insumos farmacêuticos e correlatos, cosméticos saneantes e outros produtos, e dá outras providências. Diário Oficial União. 24 set 1976.

24. Brasil. Lei $N^{\circ} 6.437$, de 20 de agosto de 1977 . Configura infrações à legislação sanitária federal, estabelece as sanções respectivas, e dá outras providências. Diário Oficial União. 24 ago 1977.
25. Agência Nacional de Vigilância Sanitária - Anvisa. Resolução RDC $N^{\circ} 36$, de 26 de agosto de 2015. Dispõe sobre a classificação de risco, os regimes de controle de cadastro e registro, os requisitos de rotulagem e instruções de uso de produtos para diagnóstico in vitro, inclusive seus instrumentos e dá outras providências. Diário Oficial União. 27 ago 2015.

26. Ministério da Saúde (BR). Aviso de chamamento público, de 17 de março de 2020. Convoca empresas a fornecerem os portfólios dos insumos para diagnóstico do COVID-19 à Coordenação Geral de Laboratórios de Saúde Pública (GGLAB), os quais destinar-se-ão ao atendimento das necessidades do Sistema Único de Saúde e à realização de um diálogo, a respeito do tema em questão, entre o setor produtivo e o Ministério da Saúde. Diário Oficial União. 18 mar 2020.

27. Agência Nacional de Vigilância Sanitária - Anvisa. Resolução RDC N ${ }^{\circ} 379$, de 30 de abril de 2020. Altera a resolução RDC No 356, de 23 de março de 2020, que dispõe de forma extraordinária e temporária, sobre os requisitos para a fabricação, importação e aquisição de dispositivos médicos de saúde, em virtude da emergência pública internacional relacionada ao SARS-CoV-2. Diário Oficial União. 4 maio 2020.

28. Bastos ML, Tavaziva G, Abidi SK, Campbell JR, Haraoui LP, Johnston JC et al. Diagnostic accuracy of serological tests for COVID-19: systematic review and meta-analysis. BMJ. 2020;370:1-13. https://doi.org/10.1136bmjm2516

29. Castro R, Luz PM, Wakimoto MD, Veloso VG, Grinsztejn B, Perazzo H. COVID-19: a meta-analysis of diagnostic test accuracy of commercial assays registered in Brazil. Braz J Infect Dis. 2020:24(2):180-97. https://doi.org/10.1016/j.bjid.2020.04.003

\section{Agradecimentos}

À Sra. Margaret Guimarães secretária do Laboratório de Sangue Hemoderivados, pelo auxílio no cadastro, na organização e na solicitação de documentos referentes aos produtos. À Dra. Marília Santini e Mayumi D. Wakimoto, pela obtenção das amostras. À Fernanda Peres Sabagh, pelo empenho em disponibilizar todos os insumos utilizados no laboratório.

\section{Contribuição dos Autores}

Adati MC, Ribeiro AS, Borges HCBG - Concepção, planejamento (desenho do estudo), interpretação dos dados e redação do trabalho. Cirilo CA, Vigo DC, Passo DCD, Macedo GPS, Castro JRN, Teixeira LV, Silva MM, Guimarães PCM, Maria RIF, Maia RM, Passo RM, Cunha RS, Mendonça VF, Ribeiro YR - Planejamento (desenho do estudo) e aquisição dos dados. Araújo ACMM, Silva JG, Aquino NC - Planejamento (desenho do estudo) e revisão do trabalho. Todos os autores aprovaram a versão final do trabalho. compartilhar, reutilizar e distribuir os artigos, desde que para uso não comercial e com a citação da fonte, conferindo os devidos créditos de autoria e menção à Visa em Debate. Nesses casos, nenhuma permissão é necessária por parte dos autores ou dos editores. 